This item was submitted to Loughborough's Research Repository by the author.

Items in Figshare are protected by copyright, with all rights reserved, unless otherwise indicated.

\title{
Additional clothing increases heat load in elite female rugby sevens players
}

PLEASE CITE THE PUBLISHED VERSION

https://doi.org/10.1123/ijspp.2020-0620

PUBLISHER

Human Kinetics

VERSION

AM (Accepted Manuscript)

PUBLISHER STATEMENT

This paper was accepted for publication in the journal International Journal of Sports Physiology and Performance and the definitive published version is available at https://doi.org/10.1123/ijspp.2020-0620

\section{LICENCE}

CC BY-NC-ND 4.0

\section{REPOSITORY RECORD}

Henderson, Mitchell J, Bryna CR Chrismas, Christopher J Stevens, Andrew Novak, Job Fransen, Aaron J Coutts, and Lee Taylor. 2021. "Additional Clothing Increases Heat Load in Elite Female Rugby Sevens Players". Loughborough University. https://hdl.handle.net/2134/16761106.v1. 
1 Title: Additional clothing increases heat-load in elite female rugby sevens players

Authors: Mitchell J. Henderson ${ }^{1,2,3}$, Bryna C.R. Chrismas ${ }^{4}$, Christopher J. Stevens ${ }^{5}$, Andrew Novak $^{1,2,3}$, Job Fransen ${ }^{1,3}$, Aaron J. Coutts ${ }^{1,3}$, Lee Taylor ${ }^{6,1,3,7^{*}}$

\section{Affiliations:}

${ }^{1}$ University of Technology Sydney (UTS), School of Sport, Exercise and Rehabilitation, Faculty of Health, Australia.

$11{ }^{2}$ Rugby Australia (RA), Sydney, Australia.

$12{ }^{3}$ University of Technology Sydney (UTS), Human Performance Research Centre, Australia.

$13{ }^{4}$ Qatar University, Sport Science Program, College of Arts and Science, Doha, Qatar.

$14{ }^{5}$ Southern Cross University, School of Health and Human Sciences, Coffs Harbour, Australia.

$15{ }^{6}$ Loughborough University, School of Sport, Exercise and Health Sciences, Loughborough, 16 UK.

$17{ }^{7}$ ASPETAR, Qatar Orthopaedic and Sports Medicine Hospital, Athlete Health and 18 Performance Research Centre, Doha, Qatar.

\section{*Address for Correspondence}

21 Dr Lee Taylor, Loughborough University, School of Sport, Exercise and Health Sciences, Loughborough, Leicestershire, LE11 3TU, UK.

Email: 1.taylor2@1boro.ac.uk Phone:+44 1509226302

Preferred Running Head: Additional clothing heat-load rugby sevens

Abstract word count: 260 


\section{Abstract}

42 Purpose: To (1) determine whether elite female rugby sevens players are exposed to core temperatures $(\mathrm{Tc})$ during training in the heat that replicate the temperate match demands previously reported, and (2) investigate whether additional clothing worn during a hot training session meaningfully increases the heat load experienced. Methods: A randomised parallel group study design was employed with all players completing the same approximately 70 minute training session $\left(27.5-34.8^{\circ} \mathrm{C}\right.$ wet bulb globe temperature $)$ and wearing a standardised training ensemble (synthetic rugby shorts and training tee [control $(\mathrm{CON}) ; \mathrm{n}=8)$ ] or additional clothing (standardised training ensemble plus compression garments and full tracksuit [additional clothing (AC); $\mathrm{n}=6]$ ]). Groupwise differences in Tc, sweat rate, GPS-measured external locomotive output, rating of perceived exertion (RPE), and perceptual thermal load were compared. Results: Mean $\left(p=0.006, \eta_{p}^{2}=0.88\right)$ and peak $\left(p<0.001, \eta_{p}^{2}=0.97\right)$ Tc was higher in AC compared to $\mathrm{CON}$ during the training session. There were no differences in external load $\left[\mathrm{F}(4,9)=0.155, p=0.956\right.$, Wilk's $\left.\Lambda=0.935, \eta_{p}^{2}=0.06\right]$ or sweat rate $(p=0.054$ Cohen's $d=1.09)$. Higher RPE ( $p=0.016$, Cohen's $d=1.49$ ) was observed in AC compared to CON. No EHI symptomology was reported in either group. Conclusions: Player Tc is similar between training performed in hot environments and match play in temperate conditions when involved for $>6 \mathrm{~min}$. Additional clothing is a viable and effective method to increase heat strain in female rugby sevens players without compromising training specificity or external locomotive capacity.

63 Keywords: core temperature, team sport, intermittent sport 
67 Physical preparation best practices for hot and humid competition conditions require carefully 68 prescribed and controlled heat stress [i.e. heat acclimation or acclimatization; (HA)] to promote 69 optimal performance. ${ }^{1,2}$ Appropriate training prescription [typically active (i.e. exercise) heat $70 \operatorname{load}^{3}$ ] promotes physiological adaptations likely to benefit physical capacity/performance in such environments [e.g. reduced resting/exercising core temperatures (Tc) and heart rates (HR), earlier and greater sweat response, greater plasma volume and exercise capacity $\left.{ }^{2}\right]$. Typical physiological responses to match play in elite women's rugby sevens include high Tc (peak Tc responses from match play: $\left.37.9-39.8^{\circ} \mathrm{C}\right)^{4}$, and HR intensities (most playing time spent between 81 and $90 \%$ of maximal HR). ${ }^{5}$ Whether routine training for rugby sevens in hot conditions generates the high thermal load observed in elite female match-play [peak Tc median (range) when involved in $>6$ min match play: $\left.39.3^{\circ} \mathrm{C}\left(38.2-39.8^{\circ} \mathrm{C}\right)\right]$ within modest wet bulb globe temperatures (WBGT; $18.5-20.1^{\circ} \mathrm{C}$ ), ${ }^{4}$ has not been established. Evidently, any disparity in this relationship has ramifications for physical preparation strategies - especially relative to the likely higher Tc that would be observed in this population during match-play in higher WBGT environments (e.g. Tokyo Olympics) compared to the predominately temperate match-play data currently available., ${ }^{4,6}$

Common barriers to best practice HA preparation in team sports include financial (travelling to appropriate locations or hiring of facilities with simulated environmental rooms can be expensive) and time constraints (team sports often have congested preparation/competition schedules and are commonly time-poor). A practical option available to all practitioners and teams is wearing additional clothing during physical preparation. This intervention promotes psycho-physiological responses implicated in successful HA protocols [e.g. elevated: Tc and skin temperature (Tsk), sweat-rate, thermal sensation/discomfort, and $\mathrm{HR}^{2}$ ] without the need 
90 for hot ambient conditions. ${ }^{7}$ Therefore, additional clothing may provide a practically 91 compatible and cheap tool to off-set (partially or otherwise) any potential thermal mismatch 92 between training and matches, increasing training specificity. Many athletes and teams 93 preparing for the Olympic Games in Tokyo (expected to be the hottest modern Olympics to 94 date; $\sim 30^{\circ} \mathrm{C}$ and relative humidity exceeding $75 \%^{8}$ ) will be training in temperate or cold 95 environments not conducive to HA. Data regarding the thermal dose response to training in 96 additional clothing compared to a control condition is generally lacking within elite team sport 97 populations, particularly females, thus evidence-based decision-making and practice within 98 this paradigm is currently challenging.

99 This study aims to (1) determine whether elite female rugby sevens players are exposed to a

100 Tc during training in the heat that replicates the temperate match demands previously reported; ${ }^{4}$ 101 and, (2) investigate whether additional clothing worn during a full rugby sevens training 102 session in the heat increases the heat load experienced. It is hypothesised that (i) peak Tc and 103 change from baseline to peak during training will not reach the magnitudes observed from 104 available match play data, and (ii) additional clothing worn during an on-field rugby sevens 105 training session will meaningfully increase heat load compared to control without any effect on GPS-derived external locomotive output.

\section{Methods}

\section{Subjects}

*** Table 1 near here please $* * *$

110 Data were collected from a total of 14 seasonally heat-acclimatised female athletes (see Table

1111 for details) from a single 2018-19 World Rugby Women's Sevens Series team based in 112 Sydney, Australia. The full population of professionally contracted international female rugby 
113 sevens athletes in the country, fit at the time of data collection, were recruited. Written

114 informed consent was provided for the project under ethical approval from the Southern Cross

115 University (ECN-18-216) and University of Technology Sydney (ETH19-4051) Human

116 Research Ethics Committees in the spirit of the Helsinki Declaration.

\section{Design}

118 A randomised parallel group study design was employed with all players simultaneously

119 completing the same 70 min training session, wearing (i) standardised training ensemble

120 (synthetic rugby shorts and training tee; $\mathrm{CON}$ ) or (ii) additional clothing [(i) plus compression

121 garments and full tracksuit; AC]. Players had been in the same time zone $\geq 14$ days prior to the

122 training session, thus circadian misalignment in Tc was not a confounding influence. In line

123 with common elite team sport practice, menstrual cycle could not be standardised.

\section{Methodology}

125 Players ingested an e-Celsius ${ }^{\mathrm{TM}}$ telemetric capsule (BodyCap, Caen, France) the night prior to 126 the training session. Tc data was only included within the statistical model when $\geq 5$ hours had 127 elapsed post-ingestion, a criteria used previously to ensure the capsule was in the lower 128 intestine. , $^{4,9}$ Tc was sampled at 30 second intervals, with data downloaded at the end of the 129 training session via a wireless data receiver (e-Viewer, BodyCap, Caen, France). Capsules were 130 prepared, calibrated, and handled as outlined previously. ${ }^{4,6,10}$ The e-Celsius ${ }^{\mathrm{TM}}$ system has been 131 determined valid and reliable for intermittent-running exercise, ${ }^{10}$ as well as excellent validity 132 (ICC 1.00), test-retest reliability (ICC 1.00) and inertia in water bath experiments between $13336^{\circ} \mathrm{C}$ and $44^{\circ} \mathrm{C},{ }^{11}$ and has been used previously within elite rugby sevens matches ${ }^{4,6}$ and

134 training. ${ }^{12}$ In the case of the capsule having been passed prior to the training session (this 135 occurred for one athlete from $\mathrm{AC}$ and two from $\mathrm{CON})$, Tc data was not able to be collected. 
136 Wet bulb globe temperature (WBGT) (SD-2010, Reed Instruments, Wilmington, NC, USA)

137 was obtained immediately prior to, during and post training session. Conditions across the data

138 collection period were generally hot $\left(27.8-34.8^{\circ} \mathrm{C}\right.$ WGBT $)$. Signs and symptoms of exertional

139 heat illnesses (EHI) were collected following the training session using a modified survey

140 instrument. ${ }^{13}$ Specifically, the athletes were asked in a yes/no manner if they had experienced

141 (i) cramping; (ii) vomiting; (iii) nausea; (iv) severe headache; (v) collapsing/fainting; or (vi) any other symptom that might relate to heat illness. ${ }^{13}$

143 Whole-body sweat loss was quantified by determining the change in body mass pre- and post-

144 training (assuming a fluid volume of $1 \mathrm{~L}=1 \mathrm{~kg}$ ). Players were asked to urinate and/or defecate,

145 if necessary, prior to pre-training measurement and not again until post-training measurement.

146 Body mass was measured wearing only underwear, immediately before and after the training

147 session using calibrated scales (BWB-800-S, Tanita, Tokyo, Japan). Each player was provided

148 with an individually named drink bottle that was weighed before and after training to establish

149 the volume consumed during the training session. Body mass loss was corrected for both fluid

150 intake and urine output but was not corrected for respiratory and metabolic water loss/gain.

151 Drinking behaviour was monitored by the researchers and practitioners to ensure players only

152 drank from their own bottle, did not spit water out, or pour water on themselves.

153 Activity profiles during the session were measured using $10 \mathrm{~Hz}$ GPS devices (EVO, GPSports,

154 Canberra, Australia). These have shown good inter-unit reliability for distance (in metres;

155 coefficient of variation $[\mathrm{CV}] \pm 90 \%$ confidence limits: $0.2 \% \pm 1.5$ ), average speed (in metres

156 per minute $\left[\mathrm{m} \cdot \mathrm{min}^{-1}\right] ; 0.2 \% \pm 1.5$ ), max velocity (in metres per second $\left[\mathrm{m} \cdot \mathrm{s}^{-1}\right] ; 0.2 \% \pm 1.5$ ),

157 high-speed running (distance covered $>5 \mathrm{~m} \cdot \mathrm{s}^{-1} ; 0.5 \% \pm 1.5$ ), and average

158 acceleration/deceleration (in metres per second squared $\left.\left[\mathrm{m} \cdot \mathrm{s}^{-2}\right] ; 1.2 \% \pm 1.5\right) .{ }^{14}$ Each unit was

159 assigned to an individual player and worn underneath their training shirt in a small upper body 
160 garment custom designed by the device manufacturer, positioning the unit between the scapula

161 blades of the player. Following the session, stored data were downloaded from the devices

162 using the manufacturer's proprietary software (GPSports Console, GPSports, Canberra,

163 Australia). Metrics exported from the GPS data included training duration (min), average speed

$164\left(\mathrm{~m} \cdot \mathrm{min}^{-1}\right)$, high-speed running per minute $\left(\mathrm{HSR} \cdot \mathrm{min}^{-1}\right.$; average distance covered $>5 \mathrm{~m} \cdot \mathrm{s}^{-1}$ per

165 minute), very high-speed running per minute $\left(\mathrm{VHSR} \cdot \mathrm{min}^{-1}\right.$; average distance covered $>6 \mathrm{~m} \cdot \mathrm{s}^{-}$

$166{ }^{1}$ per minute), and average absolute acceleration/deceleration (Ave Acc/Dec; $\mathrm{m} \cdot \mathrm{s}^{-2}$ ).

167 Thermal sensation (TS) was measured using a 17-point category ratio scale (where $0=$ 168 'unbearably cold' and $8=$ 'unbearably hot'). ${ }^{15}$ Thermal comfort (TC) was measured using a 169 10-point ordinal scale (where $1=$ 'comfortable' and $10=+1$ above 'extremely 170 uncomfortable'). ${ }^{16}$ Both TS and TC represents how players were feeling when asked (i.e. not

171 a session average). Session rating of perceived exertion (RPE) was measured using the

172 Category-Ratio scale $(\mathrm{CR}-10$; where $0=$ rest and $10=$ maximal $) .{ }^{16}$

\section{Statistical Analyses}

174 All statistical analyses were performed, and figures created, using $\mathrm{R}$ statistical software. ${ }^{17}$

175 Descriptive statistics are reported as median and range (minimum - maximum) unless

176 otherwise stated. Individual player Tc was collected and averaged for each period, with peak

177 Tc values extracted and individual player change from baseline calculated. Differences

178 between present findings and available match data previously reported ${ }^{4}$ were assessed using a one-tailed Welch's $t$-test to account for the observed unequal variances.

180 Core temperature: A linear mixed effects analysis was performed using the $\operatorname{lme} 4^{18}$ and

181 lmerTest $^{19}$ packages in $\mathrm{R}$ statistical software ${ }^{17}$ to determine the relationship between wearing 182 additional clothing during training and Tc measures at different time points during the session 
183 (baseline, training average, and training peak). As fixed effects, experimental group and 184 timepoint (with interaction term) were entered into the model including a random intercept to 185 specify repeated measures for each player. P-values were obtained by Kenward-Roger 186 approximation ${ }^{20}$ which has been shown to produce acceptable Type 1 error rates even for 187 smaller samples. ${ }^{21}$ Approximate partial eta squared effect sizes $\left(\eta_{p}^{2}\right)$ were converted from test 188 statistics and degrees of freedom using the effectsize $\mathrm{R}$ package. ${ }^{22}$

189 Sweat rate: A one-tailed Mann Whitney U test was used to determine if AC increased sweat 190 rate compared to CON. Normality and equal variance assumptions were checked using the 191 Shapiro-Wilk Test of Normality and Levene's Test respectively, and the non-parametric Mann192 Whitney U test was chosen to account for the observed violation of normality.

193 External load: A multivariate analysis of variance was performed on the collected GPS metrics

$194\left(\mathrm{~m} \cdot \mathrm{min}^{-1}, \mathrm{HSR} \cdot \mathrm{min}^{-1}, \mathrm{VHSR} \cdot \mathrm{min}^{-1}\right.$, and Ave Acc/Dec $)$ to assess group differences in 195 locomotion. Assumptions of homogeneity and multivariate normality were checked using 196 Box's Homogeneity of Covariance Matrices Test $(p=0.666)$ and Shapiro-Wilk Multivariate 197 Normality Test $(p=0.061)$, respectively.

198 Perceptual measures: A one-tailed Mann-Whitney U test was performed to assess differences 199 in RPE between AC and CON. As TS and TC are ordinal data, it would be inappropriate to 200 make statistical inferences from tests requiring a continuous dependent variable (despite 201 similar data sets using an array of these approaches previously ${ }^{23,24}$ ). To perform the appropriate 202 ordinal regression on this data, a larger sample would be required and is likely not possible 203 with one rugby sevens team and 17-point (TS) and 10-point (TC) scales. Therefore, TS and TC 204 are provided as central tendency (median) and dispersion (range) (see Figure 5) and discussed only in raw unit changes/comparisons. 
207 Raw data for Tc, sweat rate, external load, and perceptual measures for all players are presented 208 in Tables 2, 3, and 4, respectively. *** Tables 2, 3, and 4 near here please ***

210 Core temperature: The association between wearing additional clothing and session time point 211 (with interaction) on player Tc is presented in Figure 1 and Table 5. This model displayed a 212 marginal $\mathrm{R}^{2}$ value (indicating explained variance from fixed effects only) of 0.94 and a 213 conditional $\mathrm{R}^{2}$ value (indicating explained variance from both fixed and random effects) of 214 0.98. The baseline Tc reading did not differ between groups [CON: $37.2^{\circ} \mathrm{C}(36.7-37.5), \mathrm{AC}$ : $21537.1(36.6-37.2) ; p=0.356]$, but the mean and peak Tc of $\mathrm{AC}$ [mean: $38.4^{\circ} \mathrm{C}\left(38.1-38.7^{\circ} \mathrm{C}\right)$; 216 peak: $39.8^{\circ} \mathrm{C}\left(39.5-40.4^{\circ} \mathrm{C}\right)$ ] was higher compared to $\mathrm{CON}$ [mean: $38.2^{\circ} \mathrm{C}\left(37.7-38.4^{\circ} \mathrm{C}\right)$; 217 peak: $\left.39.2^{\circ} \mathrm{C}\left(38.7-39.4^{\circ} \mathrm{C}\right)\right]$ during the training session $\left(p=0.006, \eta_{p}^{2}=0.88\right.$ and $p<0.001$, $218 \eta_{p}^{2}=0.97$ respectively). Visual inspection of residual plots did not reveal any obvious 219 deviations from homoscedasticity or normality, and the Shapiro-Wilk test performed on the 220 model residuals suggested no evidence of non-normality $(p=0.798)$.

*** Figure 1 near here please $* * *$ *** Table 5 near here please $* * *$

224 Sweat rate: No difference in sweat rate was found between groups (median in CON $=1.41$ $225 \mathrm{~L} / \mathrm{hr}^{-1}$, median in $\mathrm{AC}=1.64 \mathrm{~L} / \mathrm{hr}^{-1} ; U=11.0 ; p=0.054$, Cohen's $d=1.09 ;$ see Figure 3). 
External load: The multivariate analysis found no difference in external load between AC and

$\operatorname{CON}\left(\mathrm{F}[4,9]=0.155, p=0.956, \eta_{p}^{2}[95 \% \mathrm{CI}]=0.06[0.00-0.13] ;\right.$ Wilk's $\left.\Lambda=0.935\right)$.

229

230

231

232

234

235

236

237

238

Perceptual measures: There was an increase in RPE values in AC compared to CON $(U=$ 8.00, $p=0.016$, Cohen's $d=1.49$; see Figure 4).

*** Figure 4 near here please $* * *$

Raw unit increase in TS was $3(3-5)$ in AC and $3(2-4)$ in CON. Raw unit increase in TC was $7.5(7-8)$ in $\mathrm{AC}$ and $5.5(4-6)$ in $\mathrm{CON}$.

*** Figure 5 near here please $* * *$

No EHI symptomology was reported in either group.

\section{Discussion}

The peak Tc $\left[39.2^{\circ} \mathrm{C}\left(38.7-39.4^{\circ} \mathrm{C}\right)\right]$ and change from baseline to peak Tc $\left[2.0^{\circ} \mathrm{C}(1.9-\right.$ $\left.2.4^{\circ} \mathrm{C}\right)$ ] observed throughout the training session $\left(27.5-34.8^{\circ} \mathrm{C}\right.$ WBGT) in CON (i.e. normal training clothes) did not differ to the magnitudes reported from temperate match play (18.5$20.1^{\circ} \mathrm{C}$ WBGT) when involved for at least 6 min $\left[\right.$ peak: $39.3^{\circ} \mathrm{C}\left(38.2-39.8^{\circ} \mathrm{C}\right), p=0.433$; change from baseline to peak: $\left.2.0^{\circ} \mathrm{C}\left(0.9-2.5^{\circ} \mathrm{C}\right), p=0.906^{4}\right]$. This rejects experimental hypothesis (i) that theorised Tc in hot training would not reach magnitudes observed during temperate match play [although the contrasting ambient WBGT between the present study (27.5 - 34.8 WBGT ) and the previously published match-play data ${ }^{4}(18.5-20.1$ WBGT) ensures these comparisons must be carefully interpreted]. Thermal load (as measured by player $\mathrm{Tc})$, TS, and $\mathrm{TC}$, were greater in $\mathrm{AC}$ compared to $\mathrm{CON}$, without compromising training specificity or external locomotive capacity (i.e. GPS), in support of experimental hypothesis (ii). 
249 As sporting teams approach competition, training specificity is increasingly prioritised to 250 maximise transfer to sporting movements. ${ }^{25}$ As such, practitioners tasked with preparing rugby 251 sevens teams for tournaments should be aware of the likely thermal demands of tournaments 252 (combination of predicted approximate physical demands and environmental conditions) and ensure appropriate training (e.g. HA) occurs to develop the necessary adaptations to maximise performance and protect athlete health [particularly in female athletes who may be more susceptible to hyperthermia ${ }^{4}$. This is the first study to directly compare player Tc recorded in training to the only available match play Tc data in women's rugby sevens. The findings support that training in hot environments $\left(27.5-34.8^{\circ} \mathrm{C}\right.$ WBGT in the current study) may provide a comparable heat stress to the previously reported temperate match-play data, albeit and emphasising an important distinction, in temperate $\left(18.5-20.1^{\circ} \mathrm{C}\right.$ WBGT $)$ match-play conditions ${ }^{4}$ compared to the hot $\left(27.5-34.8^{\circ} \mathrm{C}\right.$ WBGT $)$ training conditions in the present study (Figure 1). Given training in hot conditions generates a comparable thermal load to temperate match-play, it seems logical (as shown elsewhere ${ }^{26}$ ) that the responses to matches in hot conditions would likely not be replicated within these training conditions (i.e. players would not get hot enough in training to mimic thermal demands on hot matchdays). This expectation is based on the higher Tc observed during higher ambient temperatures in Australian rules football with comparable intermittent, high-intensity, bioenergetic demands ${ }^{26}$ to rugby sevens. $^{5}$ This may require a further intervention such as wearing additional clothing during hot training to facilitate the desired phenotypic HA signals and adaptations (e.g. decreased Tc and HR at a given intensity etc.), which in turn, provide protection against impaired performance capacity and EHI associated with exercise-induced hyperthermia. ${ }^{1}$

271 Longer term ( $>14$ days) HA strategies have been shown to provide the greatest protection to 272 performance decrements and EHI, ${ }^{1}$ yet traditionally have often been impractical in elite team 273 sport due to highly demanding physical preparation programs, pre-set competition schedules, 
and travel demands. ${ }^{27}$ The observed increases in Tc and perceived thermal load in AC are likely

to stimulate a greater physiological response compared to $\mathrm{CON}$ and may contribute to more

276 pronounced HA adaptations or faster procurement of a fully HA phenotype ${ }^{2}$; N.B. a higher

277 HA-session Tc does not always promote 'greater' HA adaptations. ${ }^{28}$ These findings provide

278 proof-of-concept for additional clothing and its ability to increase thermal load and elicit

279 associated perceptual changes within the utilised population. Adoption of additional clothing

280 within training scenarios may (subject to further confirmatory work) solve some, but not all,

281 common challenges to practice regarding barriers to HA protocols within team sports. Future

282 work should use a repeated measures design to provide more detail on the physiological

283 (including key variables associated within HA procurement not adopted within the present

284 design, e.g. HR, skin temperature, etc.), technical, and training load responses to an acute session. This could precede more prolonged additional clothing implementations within a team sport scenario and determine whether such an intervention can elicit a fully HA phenotype.

The AC group in the present study reached very high peak Tc values (range: $39.5-40.4^{\circ} \mathrm{C}$ ) but external locomotive work output was not affected compared to CON (with five of the ten drills completed after warm-up involving a degree of internally governed locomotion). It has been proposed that a $\mathrm{Tc}>39^{\circ} \mathrm{C}$ can compromise central nervous system function, ${ }^{29}$ repeat sprint ability ( $<60 \mathrm{~s}$ between efforts), ${ }^{29,30}$ and intermittent sprint performance (60-300 $\mathrm{s}$

292 between efforts), ${ }^{31}$ but the present study was not able to reproduce these locomotive movement 293 decrements, nor any undesirable EHI associated pathologies, despite surpassing the Tc 294 threshold proposed to affect performance. ${ }^{29}$ A possible explanation for this finding is that some 295 CON group Tc also surpassed $39^{\circ} \mathrm{C}$ (range: $38.7-39.4$ ), although not to the same magnitude as $\mathrm{AC}$, suggesting a potential non-linear relationship between $\mathrm{Tc}$ (greater than $39^{\circ} \mathrm{C}$ ) and

297 locomotive capacity. Similarly, meaningful differences in external locomotive capacity may 298 be hidden by the large variability observed in physical performance for rugby sevens due to 
contextual sport demands. ${ }^{32}$ This makes meaningful inferences from interventions difficult to ascertain as key physical performance measures during invasive team sports (e.g. high speed running) show poor reliability and demand practically unrealistic sample sizes [e.g. elite soccer sample required is 80 players $\left.^{33}\right]$.

303 Whilst this study provides proof-of-concept that wearing additional clothing can increase thermal load and its perception, the lack of a repeated measures design and a small sample of athletes $(n=14)$ from one team with likely similar acclimatisation status limit the broader generalisability of the findings. Although the sample size in the present investigation is limited, it represents the full population of professionally contracted international female rugby sevens athletes in the country, that were fit, at the time of data collection. Future research using a larger sample of athletes from different teams and home climates (multi-team studies likely required, albeit evidently challenging to deliver due to competitive advantage concerns) is

311 needed to provide more confidence in the comparisons between training and match play Tc.

312 Similarly, replication studies across a range of different ambient WBGT temperatures will

313 strengthen our understanding through a more robust assessment of the independent effects of 314 additional clothing interventions, and standardised comparisons of training to available match

315 Tc data. Finally, the magnitude in Tc response (see Figure 1) demonstrated some individual 316 variability (see Figure 2), which practitioners should consider when physical preparation 317 strategies for hot and humid competitions are being considered/prescribed.

\section{Practical Applications}

- Wearing additional clothing (compression garments and full tracksuit) during rugby sevens training is an accessible and valid method to achieve increased Tc and perceived exertion; without negatively affecting external locomotive output or compromising training specificity. 


\section{Conclusions}

324 Elite female rugby sevens athletes generate high Tc when competing [peak Tc median (range) 325 when involved in $>6$ min match play: $\left.39.3^{\circ} \mathrm{C}\left(38.2-39.8^{\circ} \mathrm{C}\right)\right]$ in temperate conditions. ${ }^{4}$ This 326 study showed that when training is performed in hot environments, player Tc reflect the 327 magnitudes experienced when involved in $>6$ min of match play in temperate conditions. 328 Further, previous approaches to HA have experienced limited adoption due to logistical and 329 financial obstacles in elite team sports. This research has found additional clothing to be a 330 viable and effective method to increase heat strain in elite female rugby sevens players without 331 introducing undesirable EHI associated pathologies or compromising training specificity / 332 external locomotive capacity. These findings provide evidence to rugby sevens practitioners tasked with preparing athletes for the thermal demands of the sport; and provide practitioners an accessible, evidence-based tool to help deliver a physical thermal load associated with the procurement of a HA phenotype, but further confirmatory work is required to strengthen these 336 initial findings.

\section{Declarations/Acknowledgements}

338 The authors thank the players and staff for their willingness, professionalism, engagement, and time pre, during and post the executed research project - without which - the project would not have been viable. Lee Taylor (and co-authors) thanks the Aspire Zone Foundation (AZF;

341 Doha, Qatar) for the funding and support to complete the presented research project. Additional thanks go to BodyCap (Caen, France) for the loan of 12 e-Viewers (plus general technical and logistical support) to complete the presented research project. Mitchell J. Henderson was

344 supported by the Research Training Program (RTP) scholarship (Australia) and a research

345 scholarship from Rugby Australia for this project. Aside from the above there was no further 346 potential conflict of interests for any author in this study. Each author contributed to 
experimental design, data collection and data analysis, manuscript drafting and agreed to the

submitted version of the manuscript.

\section{References}

1. Racinais $\mathrm{S}$, Alonso JM, Coutts $\mathrm{AJ}$, et al. Consensus recommendations on training and competing in the heat. Br J Sports Med. 2015;49(18):1164-1173.

2. Tyler CJ, Reeve T, Hodges GJ, Cheung SS. The Effects of Heat Adaptation on Physiology, Perception and Exercise Performance in the Heat: A Meta-Analysis. Sports Med. 2016;46(11):1699-1724.

3. Gibson OR, James CA, Mee JA, et al. Heat alleviation strategies for athletic performance: A review and practitioner guidelines. Temperature. 2019;7(1):3-36.

4. Henderson MJ, Chrismas BCR, Stevens CJ, Coutts AJ, Taylor L. Changes in Core Temperature During an Elite Female Rugby Sevens Tournament. Int J Sports Physiol Perform. 2020;15(4):571-580.

5. Suarez-Arrones L, Nuñez FJ, Portillo J, Mendez-Villanueva A. Match Running Performance and Exercise Intensity in Elite Female Rugby Sevens. The Journal of Strength \& Conditioning Research. 2012;26(7):1858-1862.

6. Taylor L, Thornton HR, Lumley N, Stevens CJ. Alterations in core temperature during World Rugby Sevens Series tournaments in temperate and warm environments. Eur J Sport Sci. 2019;19(4):432-441.

7. Tyler CJ. Maximising Performance in Hot Environments: A Problem-Based Learning Approach. Routledge; 2019.

8. Taylor L, Carter S, Stellingwerff T. Cooling at Tokyo 2020(1): the why and how for endurance and team sport athletes. Br J Sports Med. 2020.

9. Byrne C, Lim CL. The ingestible telemetric body core temperature sensor: a review of validity and exercise applications. Br J Sports Med. 2007;41(3):126-133.

10. Travers GJS, Nichols DS, Farooq A, Racinais S, Périard JD. Validation of an ingestible temperature data logging and telemetry system during exercise in the heat. Temperature (Austin). 2016;3(2):208-219.

11. Bongers C, Daanen HAM, Bogerd CP, Hopman MTE, Eijsvogels TMH. Validity, reliability, and inertia of four different temperature capsule systems. Med Sci Sports Exerc. 2018;50(1):169-175.

12. Taylor L, Stevens CJ, Thornton HR, Poulos N, Chrismas BCR. Limiting the Rise in Core Temperature During a Rugby Sevens Warm-Up With an Ice Vest. Int J Sports Physiol Perform. 2019;14(9):1212-1218.

13. Periard JD, Racinais S, Timpka T, et al. Strategies and factors associated with preparing for competing in the heat: a cohort study at the 2015 IAAF World Athletics Championships. Br J Sports Med. 2017;51(4):264-270.

14. Thornton HR, Nelson AR, Delaney JA, Serpiello FR, Duthie GM. Interunit reliability and effect of data-processing methods of Global Positioning Systems. Int J Sports Physiol Perform. 2019;14(4):432-438.

15. Young AJ, Sawka MN, Epstein Y, Decristofano B, Pandolf KB. Cooling different body surfaces during upper and lower body exercise. J Appl Physiol. 1987;63(3):1218-1223.

16. Borg GA. Psychophysical bases of perceived exertion. Med Sci Sports Exerc. 1982;14(5):377-381.

17. R Core Team. R: A language and environment for statistical computing. R Foundation for Statistical Computing, Vienna, Austria. 2019: https://www.R-project.org/. 
18. Bates D, Maechler M, Bolker B, Walker S. Fitting linear mixed-effects models using lme4. J Stat Softw. 2015;67(1):1-48.

19. Kuznetsova A, Brockhoff PB, Christensen RHB. lmerTest: Tests in linear mixed effects models. J Stat Softw. 2016;82(13):1-26.

20. Kenward MG, Roger JH. Small Sample Inference for Fixed Effects from Restricted Maximum Likelihood. Biometrics. 1997;53(3):983-997.

21. Luke SG. Evaluating significance in linear mixed-effects models in R. Behav Res Methods. 2017;49(4):1494-1502.

22. Ben-Shachar MS, Makowski D, Lüdecke D. Compute and interpret indices of effect size. R package. 2020; https://github.com/easystats/effectsize.

23. Périard JD, Racinais S, Knez WL, Herrera CP, Christian RJ, Girard O. Thermal, physiological and perceptual strain mediate alterations in match-play tennis under heat stress. Br J Sports Med. 2014;48(Suppl 1):i32.

24. Stephens J, Argus C, Driller M. The Relationship between Body Composition and Thermal Responses to Hot and Cold Water Immersion. J Hum Perform Extreme Environ. 2014;11:1.

25. Brearley S, Bishop C. Transfer of Training: How Specific Should We Be? Strength Cond J. 2019;41(3):97-109.

26. Aughey RJ, Goodman CA, McKenna MJ. Greater chance of high core temperatures with modified pacing strategy during team sport in the heat. J Sci Med Sport. 2014;17(1):113-118.

27. Casadio JR, Kilding AE, Cotter JD, Laursen PB. From Lab to Real World: Heat Acclimation Considerations for Elite Athletes. Sports Med. 2017;47(8):1467-1476.

28. Gibson OR, Mee JA, Tuttle JA, Taylor L, Watt PW, Maxwell NS. Isothermic and fixed intensity heat acclimation methods induce similar heat adaptation following short and long-term timescales. Journal of thermal biology. 2015;49-50:55-65.

29. Girard O, Brocherie F, Bishop DJ. Sprint performance under heat stress: A review. Scand J Med Sci Sports. 2015;25 Suppl 1:79-89.

30. Drust B, Rasmussen P, Mohr M, Nielsen B, Nybo L. Elevations in core and muscle temperature impairs repeated sprint performance. Acta Physiol Scand. 2005;183(2):181-190.

31. Sunderland C, Nevill ME. High-intensity intermittent running and field hockey skill performance in the heat. J Sports Sci. 2005;23(5):531-540.

32. Henderson MJ, Fransen J, McGrath JJ, Harries SK, Poulos N, Coutts AJ. Individual Factors Affecting Rugby Sevens Match Performance. Int J Sports Physiol Perform. 2019;14(5):620-626.

33. Gregson W, Drust B, Atkinson G, Di Salvo V. Match-to-Match Variability of HighSpeed Activities in Premier League Soccer. Int J Sports Med. 2010;31:237-242.

\section{Figure captions}


442

443
A

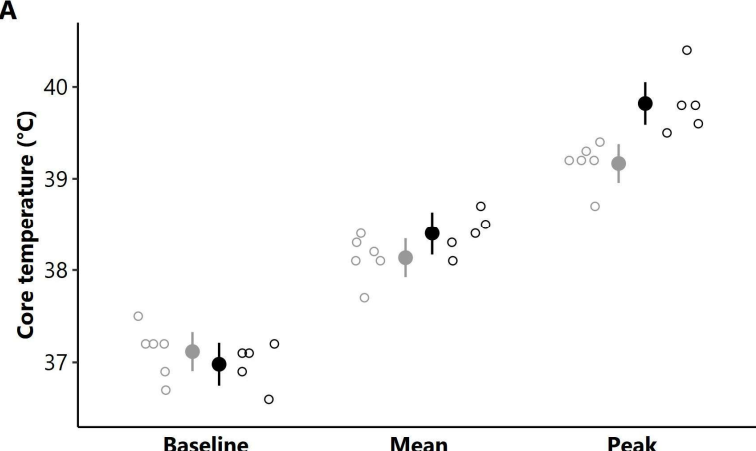

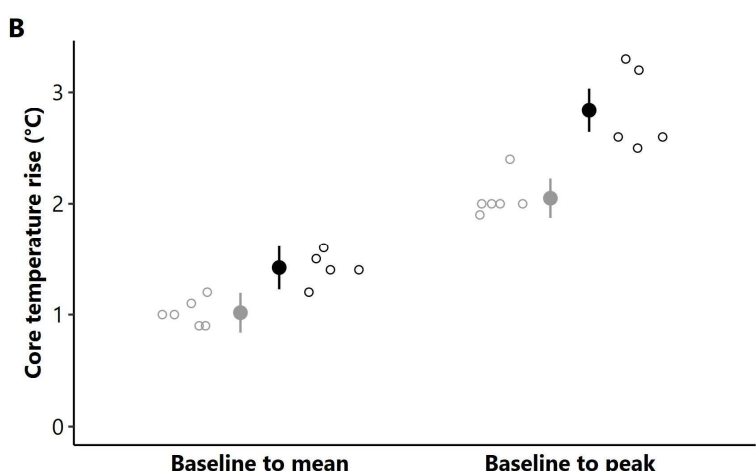

Figure 1. Individual baseline, mean, and peak core temperature (2A) and change from baseline to mean and peak core temperature (2B) for all players. Filled circles represent predicted group means from a linear mixed model at each timepoint, lines represent $95 \%$ confidence interval of the predicted group means, and unfilled circles represent individual data for additional clothing (black) and control (grey) conditions.

A

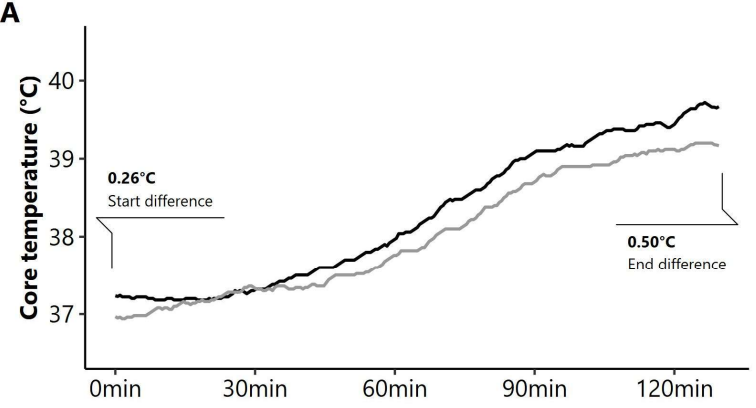

C

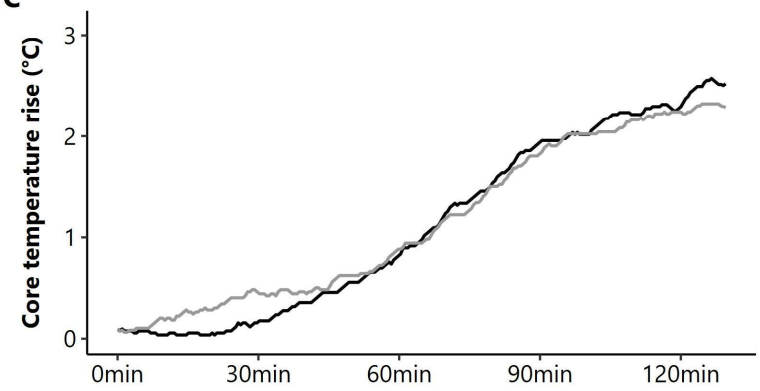

B

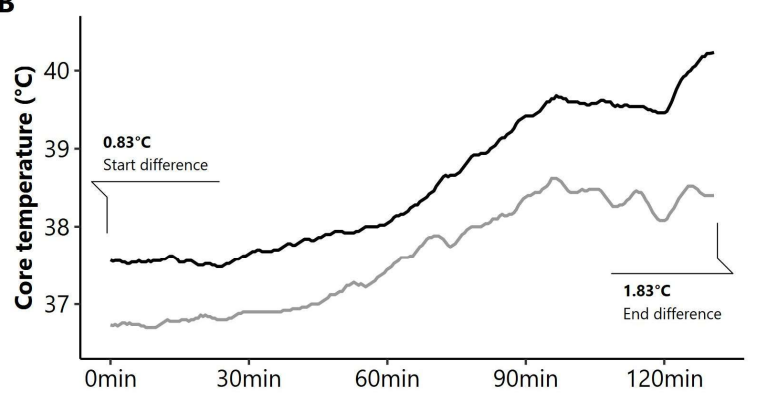

D

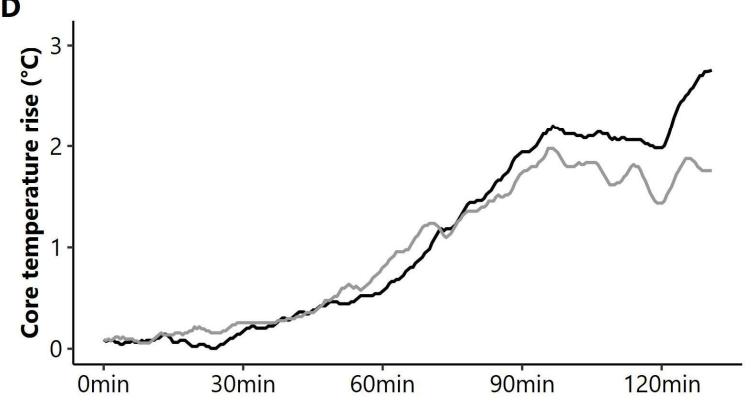

Figure 2. Individual core temperature traces during the training session for athletes recording the median peak core temperature (raw: 2A; delta: 2C) and largest peak core temperature disparity (raw: 2B; delta: 2D) in the additional clothing group (black) and control group (grey). Extremes of core temperature responses in $2 \mathrm{~B}$ and $2 \mathrm{D}$ are shown to demonstrate variability between individuals. Five-point moving mean smoothing was applied to the data to minimise noise. 


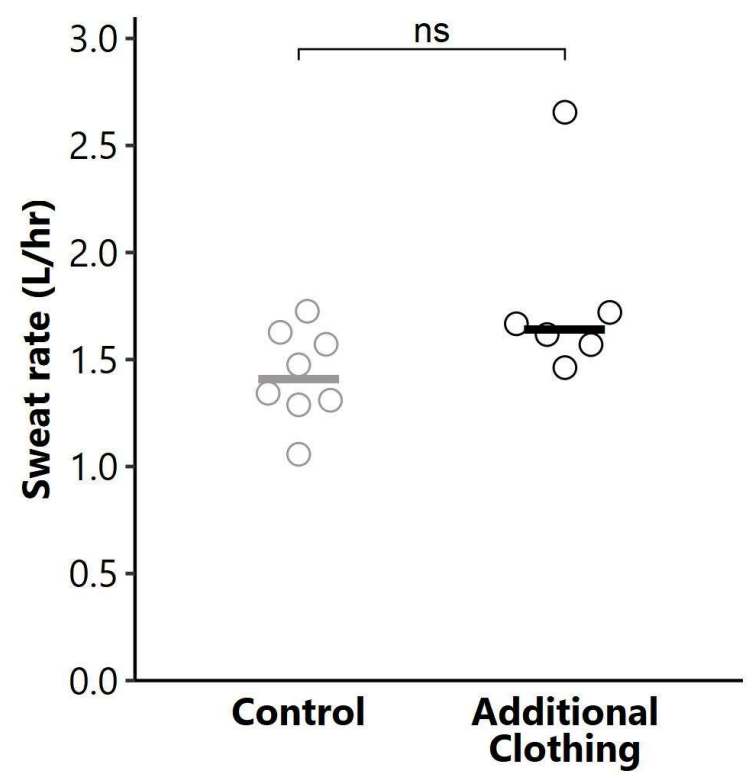

451

452

453

454

455

456

457

458

459

460

Figure 3. Individual sweat rates for all players. Solid horizontal lines represent group median and circles represent individual data for additional clothing (black) and control (grey) conditions. $\mathrm{L} / \mathrm{hr}=$ Litres per hour; $\mathrm{ns}=$ non-significant.

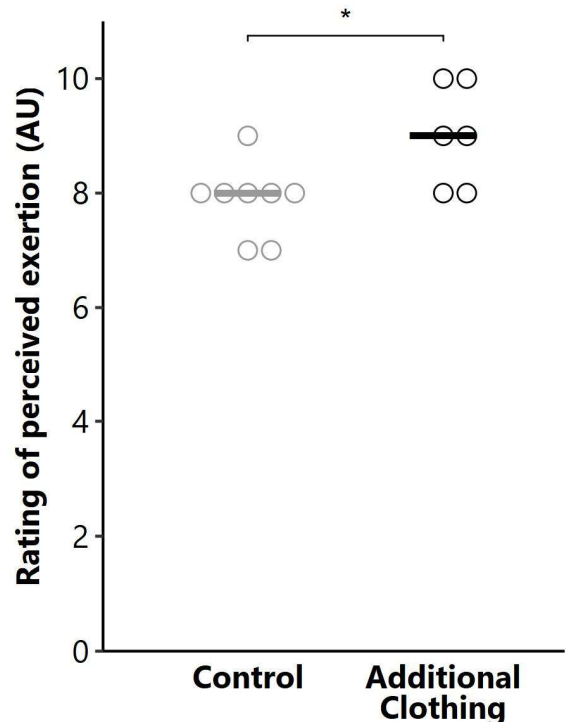

Figure 4. Individual post-session rating of perceived exertion for all players. Solid horizontal lines represent group median and circles represent individual data for additional clothing (black) and control (grey) conditions. AU = arbitrary units; * $=p<0.05$. 
A

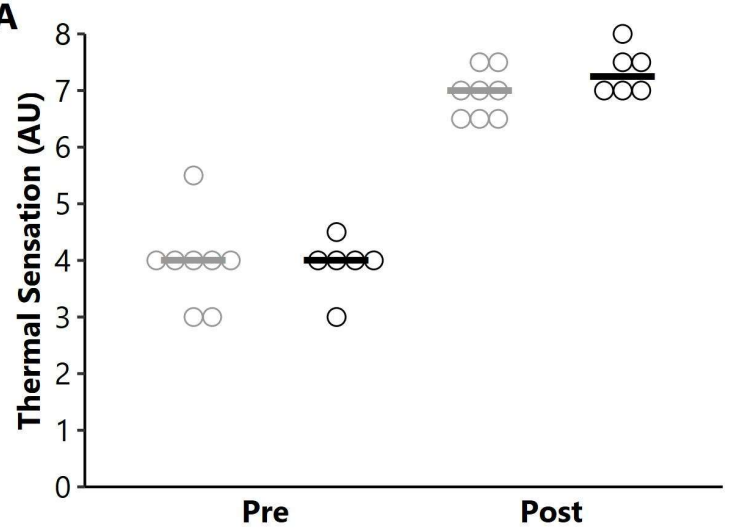

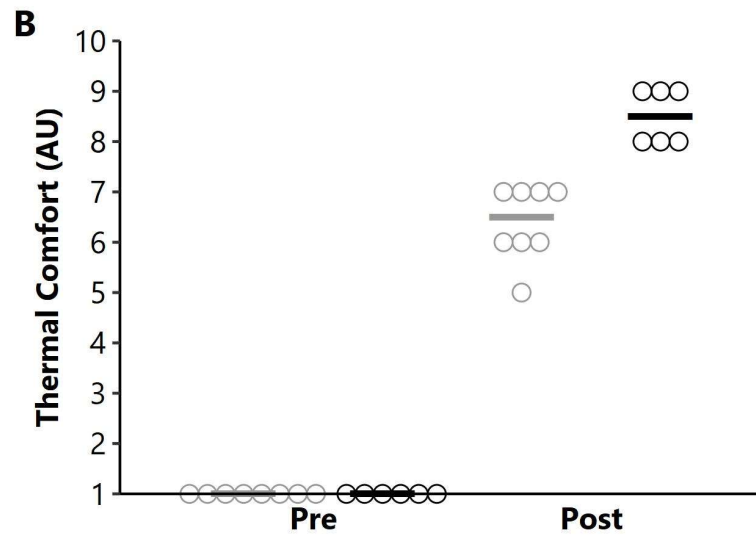

461

462

463

464

Figure 5. Individual pre- and post-session thermal sensation (5A) and thermal comfort (5B) for all players. Solid horizontal lines represent group median and circles represent individual data for additional clothing (black) and control (grey) conditions. AU = arbitrary units. 
Table 1. Player characteristics, anthropometry and body composition. Data is presented as median (minimum - maximum).

466

\begin{tabular}{lll}
\hline Measure & Control & Additional Clothing \\
\hline Age $(\mathrm{y})$ & $24(19-29)$ & $23(17-30)$ \\
Height $(\mathrm{m})$ & $1.69(1.65-1.74)$ & $1.69(1.65-1.71)$ \\
Body mass $(\mathrm{kg})$ & $67.8(59.2-74.0)$ & $67.5(63.9-77.7)$ \\
Sum SF $(\mathrm{mm})$ & $70.1(38.9-82.5)$ & $69.6(51.6-84.3)$ \\
Triceps SF $(\mathrm{mm})$ & $6.8(3.8-11.8)$ & $7.4(4.8-10.1)$ \\
Subscapular SF $(\mathrm{mm})$ & $9.4(6.5-15.2)$ & $9.6(6.9-13.5)$ \\
Bicep SF (mm) & $4.2(2.9-6.7)$ & $4.3(3.2-6.0)$ \\
Supraspinale SF (mm) & $8.2(5.2-16.8)$ & $8.5(3.8-11.3)$ \\
Abdomen SF (mm) & $11.7(8.7-20.0)$ & $11.9(7.6-13.6)$ \\
Thigh SF (mm) & $17.2(8.5-26.0)$ & $17.1(14.8-25.4)$ \\
Calf SF (mm) & $9.1(3.0-12.0)$ & $8.1(6.0-12.0)$ \\
Body fat $(\%)$ & $19.1(14.7-25.4)$ & $20.4(13.6-22.0)$ \\
LBM (kg) & $54.9(49.8-63.1)$ & $54.4(49.9-62.5)$ \\
\hline SF = skinfold; LBM = lean body mass & &
\end{tabular}


Table 2. Core body temperature (Tc) and sweat rate across each timepoint and group. Data is presented as median (range) for all players.

\begin{tabular}{|c|c|c|c|c|}
\hline Timepoint & Group & Te $\left({ }^{\circ} \mathbf{C}\right)$ & $\Delta \mathrm{Tc}$ from Baseline $\left({ }^{\circ} \mathrm{C}\right)$ & Sweat rate $(\mathrm{L} / \mathrm{hr})$ \\
\hline & Control & $37.2(36.7-37.5)$ & N/A & $\mathrm{N} / \mathrm{A}$ \\
\hline \multicolumn{5}{|l|}{ Baseline } \\
\hline & Additional Clothing & $37.1(36.6-37.2)$ & N/A & N/A \\
\hline \multirow{2}{*}{\multicolumn{5}{|c|}{$38.2(37.7-38.4)$}} \\
\hline & & & & \\
\hline & Additional Clothing & $38.4(38.1-38.7)$ & $1.4(1.2-1.6)$ & $1.64(1.46-2.66)$ \\
\hline \multirow{3}{*}{ Training Peak } & Control & $39.2(38.7-39.4)$ & $2.0(1.9-2.4)$ & N/A \\
\hline & & & & \\
\hline & Additional Clothing & $39.8(39.5-40.4)$ & $2.6(2.5-3.3)$ & N/A \\
\hline
\end{tabular}

Tc: core temperature 


\begin{tabular}{ccccc}
\hline Group & $\mathbf{m} \cdot \mathbf{m i n}^{-1}$ & HSR $\cdot \mathbf{m i n}^{-1}$ & VHSR $\cdot \mathbf{m i n}^{-1}$ & Ave Acc/Dec \\
\hline Control & $44.6(36.7-45.9)$ & $1.5(1.2-2.0)$ & $0.40(0.16-0.69)$ & $0.33(0.29-0.35)$ \\
$\begin{array}{c}\text { Additional } \\
\text { Clothing }\end{array}$ & $41.8(39.3-48.5)$ & $1.5(1.4-1.9)$ & $0.48(0.27-0.66)$ & $0.32(0.28-0.38)$ \\
\hline
\end{tabular}

$\mathrm{m} \cdot \mathrm{min}^{-1}:$ metres per minute; HSR $\cdot \mathrm{min}^{-1}:$ metres per minute covered at greater than 5 metres per second; VHSR $\cdot \mathrm{min}^{-1}:$ metres per minute covered at greater than 6 metres per second;

Ave Acc/Dec: average acceleration/deceleration in $\mathrm{m} \cdot \mathrm{s} \cdot \mathrm{s}^{-2}$.

Table 3. Global Positioning Systems (GPS) measures between experimental groups during the session. Data is presented as median (range) for all players. 


\begin{tabular}{lcccc}
\hline Period & Group & RPE & Thermal Sensation & Thermal Comfort \\
\hline Pre & Control & NA & $4.0(3.0-5.5)$ & $1.0(1.0-1.0)$ \\
& Additional Clothing & NA & $4.0(3.0-4.5)$ & $1.0(1.0-1.0)$ \\
\hline Post & Control & $8(7-9)$ & $7.0(6.5-7.5)$ & $6.5(5.0-7.0)$ \\
\hline & Additional Clothing & $9(8-10)$ & $7.3(7.0-8.0)$ & $8.5(8.0-9.0)$ \\
\hline
\end{tabular}


Table 5. Linear mixed effects model assessing the effect of experimental group and timepoint (with interaction) on player core temperature.

\begin{tabular}{|c|c|c|c|c|c|c|c|}
\hline Predictors & Estimates $(95 \%$ CI) & std. Error & $t$ & $d f$ & $p$ & $\eta_{p}^{2}(95 \% C I)$ & ES interpretation \\
\hline (Intercept) & $37.12(36.90-37.33)$ & 0.11 & 343.54 & 21.23 & $<0.001$ & & \\
\hline Control & \multicolumn{7}{|c|}{ Reference } \\
\hline Intervention & $-0.14(-0.45-0.18)$ & 0.16 & -0.85 & 21.23 & 0.408 & $0.05(0.00-0.36)$ & small \\
\hline Group: Intervention x Timepoint: Training Average & $0.40(0.15-0.66)$ & 0.13 & 3.1 & 26.89 & 0.006 & $0.88(0.75-0.93)$ & large \\
\hline Group: Intervention x Timepoint: Training Peak & $0.79(0.54-1.04)$ & 0.13 & 6.08 & 26.89 & $<\mathbf{0 . 0 0 1}$ & $0.97(0.93-0.98)$ & large \\
\hline Baseline & \multicolumn{7}{|c|}{ Reference } \\
\hline Training Average & $1.02(0.84-1.19)$ & 0.09 & 11.6 & 26.89 & $<\mathbf{0 . 0 0 1}$ & $0.35(0.04-0.61)$ & large \\
\hline Training Peak & $2.05(1.88-2.22)$ & 0.09 & 23.39 & 26.89 & $<\mathbf{0 . 0 0 1}$ & $0.67(0.37-0.81)$ & large \\
\hline $\mathrm{N}_{\text {Players }}$ & \multicolumn{7}{|c|}{11} \\
\hline Observations & \multicolumn{7}{|c|}{33} \\
\hline Marginal $\mathrm{R}^{2}$ / Conditional $\mathrm{R}^{2}$ & \multicolumn{7}{|c|}{$0.937 / 0.979$} \\
\hline
\end{tabular}

$C I$ : confidence interval; $d f$ : degrees of freedom; $\eta_{p}^{2}$ : approximate partial eta squared; $E S$ : effect size 